\title{
TRANSFUSION PATTERN OF FRESH FROZEN PLASMA AT MEDICAL UNIVERSITY HOSPITAL IN BANGLADESH
}

\author{
ADNAN SD ${ }^{1}$, BISWAS J², BEGUM HA ${ }^{3}$, HOQUE MM ${ }^{4}$, CHOWDHURY FS 5
}

\begin{abstract}
This cross sectional study was carried out at Bangabandhu Sheikh Mujib Medical University, Dhaka during the period of November 2008 to April 2009 on patients who received fresh frozen plasma. Relevant information of those patients was noted from the records kept at the Department of Transfusion Medicine. The collected data was statistically analyzed.

In this study it was observed that 939 units of FFP were required in BSMMU during study period. 289 patients required these units of FFP. The age of the patients that required FFP ranged from 1 day to 75 years. Among them highest 99 (34.25\%) were in the age group1 day to. 10 years. There were 178 (61.59\%) males and 111 (38.41\%) females. Out of 289 patients 111 (38.41\%) was B+ve, 86 (29.76\%) was O+ve, 66 (22.84\%) was A+ve and 26 (08.99\%) was $A B+v e$. According to Rh typing maximum unit 930 (99.04) units were Rh $D+v e, 9$ units (00.96\%) were Rh D-ve. Highest number of FFP Unit 329 (35.04\%) was used in day care center in transfusion medicine department. Followed by Gastro-enterology 188 (20.02\%), Burn \& Plastic surgery 140(14.91\%), Paediatrics \& allied 106 (11.29\%), Rest 176 units by other departments.

According to clinical indication highest number of FFP Unit 271 (28.86\%) was used for Hemophilia A, followed by CLD 210 (22.36\%), Burn140 (14.91\%). Distribution of the units of FFP according to rational use it was found that a large number of unit 386 (41\%) use was not clinically justified. Study shows 60 (20.77\%) patients was not supplied with correct documentation. According to requirement Transfusion Medicine alone uses 35\%, other dept of university uses 46\%, 19\% of unit is supplied to other medical centers.
\end{abstract}

Key words: Fresh frozen plasma, Transfusion, Clinical audit.

J Dhaka Med Coll. 2009; 18(2) : 132-135

\section{Introduction}

Plasma, the aqueous component of blood, consists of approximately $85-90 \%$ water, representing $6-8 \%$ of total body water $(40-50$ $\mathrm{ml} / \mathrm{kg}$ body weight), and has a density of $1.055-$ $1.063 \mathrm{~g} / \mathrm{ml}$ attributed to its various constituents, including protein and colloids $(7 \%)$, and nutrients, crystalloids, hormones, and vitamins (2-3\%). The concentration of anions, cations, and proteins in plasma confers its ionic properties. Human plasma contains more than 120 proteins with various physical and functional properties. Of these plasma proteins, albumin is the most abundant (3500-5000 mg/ dl), and among its numerous functions, it also has an important role in maintaining normal plasma colloid oncotic pressure and blood pressure. Other plasma proteins include immunoglobulins and over 20 complement components, of which $\mathrm{C} 3$ predominates at a concentration of $1200 \mathrm{mcg} / \mathrm{dl}$. One milliliter of fresh frozen plasma contains 2-3 mg fibrinogen, $60 \mathrm{mcg}$ factor XIII, 5-10 mcg von Willebrand factor (vWF), and approximately 1 unit of activity of each of the stable coagulation factors (II, VII, IX, X). The concentration of factor VIII in plasma is approximately $100 \mathrm{ng} / \mathrm{ml}$ and is found

1. Medical Officer, Department of Transfusion Medicine, DMCH, Dhaka.

2. Professor, Chairman, Department of Transfusion Medicine, BSMMU, Dhaka.

3. Associate Professor, Department of Transfusion Medicine, DMCH, Dhaka.

4. Assistant Professor, Department of Transfusion Medicine, DMCH, Dhaka.

5. Assistant Registrar, Department of Transfusion Medicine, DMCH, Dhaka.

Correspondence: Dr. Sheikh Daud Adnan 
primarily bound to vWF. Plasma also contains variable amounts of vitamins, hormones, and trace elements, although it is the protein fraction containing the coagulation factors for which plasma is most commonly prescribed ${ }^{1}$.

\section{USE OF FFP:}

1. Multiple Coagulation Factor Deficiencies:

a. The liver Disease

b. Familial Coagulation Factor Deficiencies

2. Rapid Reversal of Warfarin Effect

3. Massive Transfusion

4. Disseminated Intravascular Coagulation (DIC)

5. Thrombotic Thrombocytopenic Purpura (TTP) : Four related clinical entities with common clinical features have been described - TTP, childhood hemolytic- uraemic syndrome, adult HUS, and HELLP (a pregnancy-related syndrome of "hemolysis, elevated liver enzymes, and low platelets") ${ }^{2}$.

\section{Methodology}

This cross sectional study was carried at BSMMU for 6 months from November 2008 to April 2009 on 289 Patients who received 939 units FFP. Patients' information was noted from the records. The collected data was statistically analyzed. Patients advised for FFP transfusion for any clinical condition of all age groups and both sexes during study period are included. Patients who received whole blood or other plasma product (e.g. Albumin, Recombinant Factor VIII, etc) and patients who were advised but not supplied FFP due to incompatibility, unavailability or any other reason are excluded from the study.

\section{Results}

Results are shown in following figures:

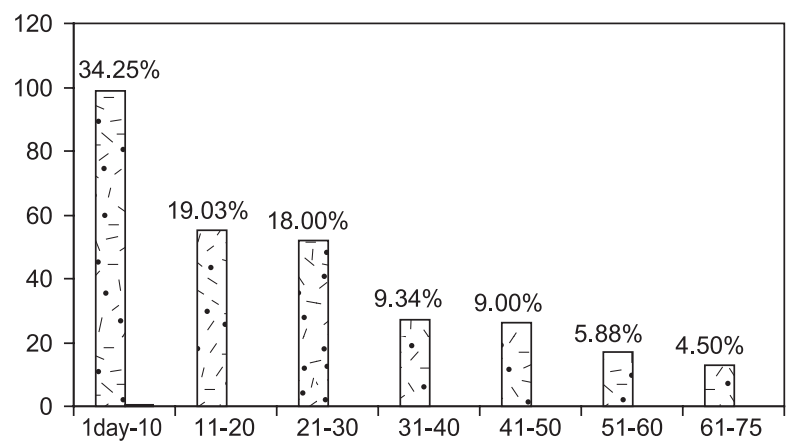

Fig 1: Distribution of patients according to age $(n=289)$.

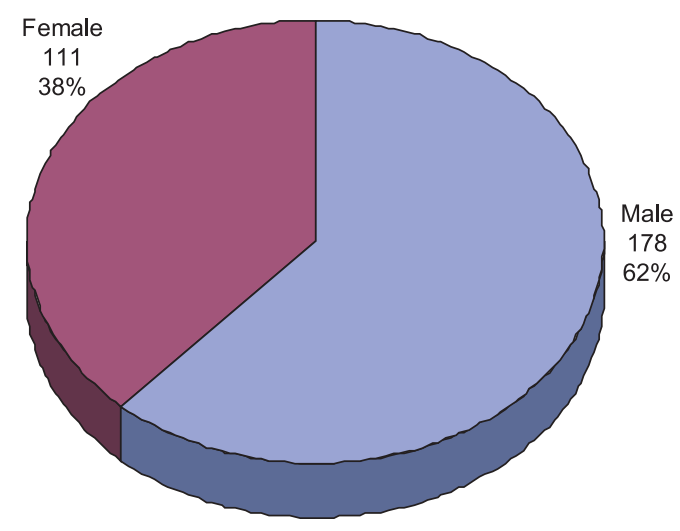

Fig 2: Distribution of patients according to sex $(n=289)$

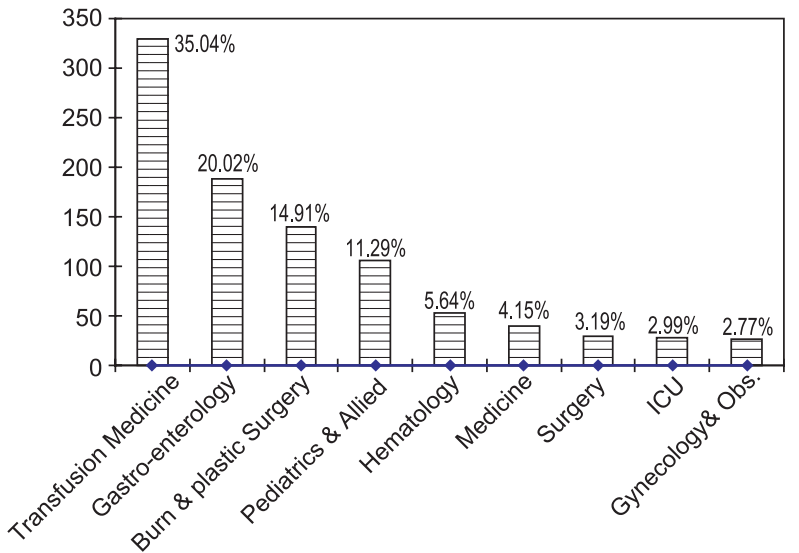

Fig 3: Distribution of FFP according to departmental requirements $(\mathrm{n}=939)$

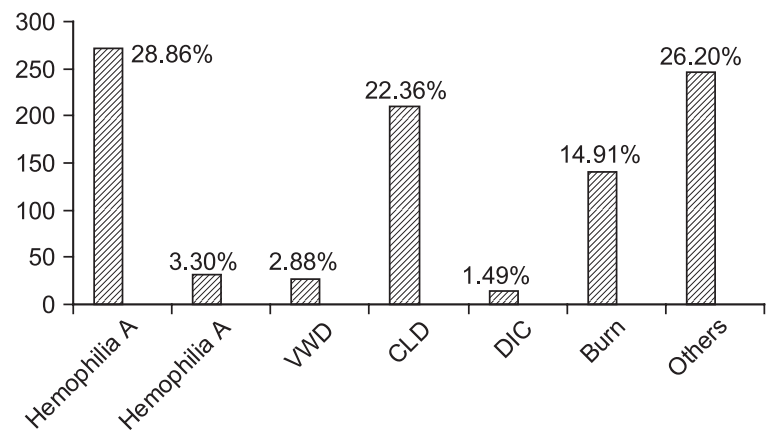

Fig 4: Distribution of FFP according to indication $(n=939)$ 


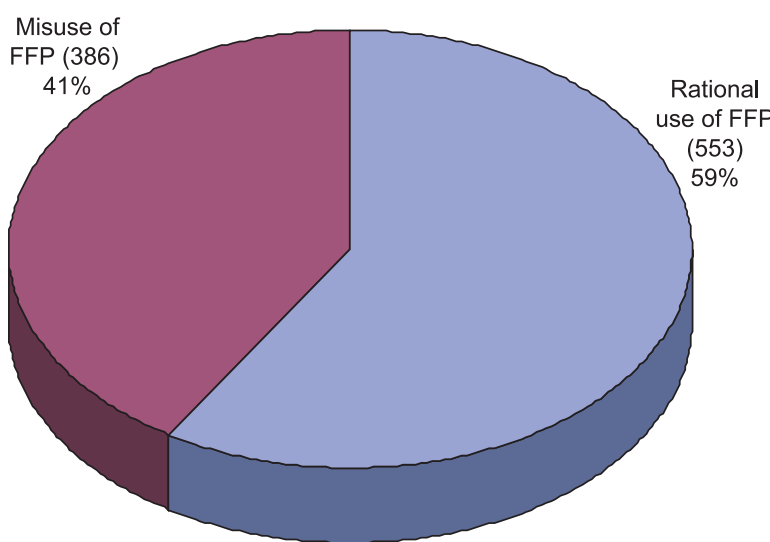

Fig 5: Distribution of FFP according to rational use

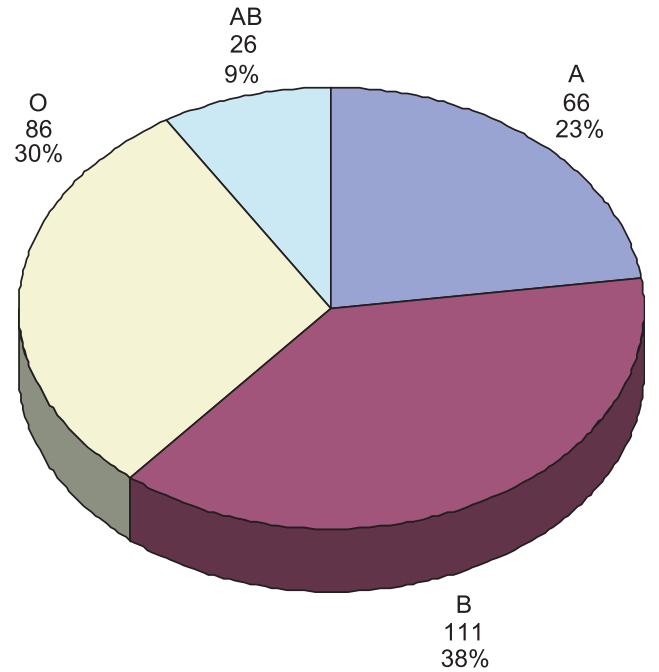

Fig 6: Distribution of FFP according to Blood Group $(n=289)$

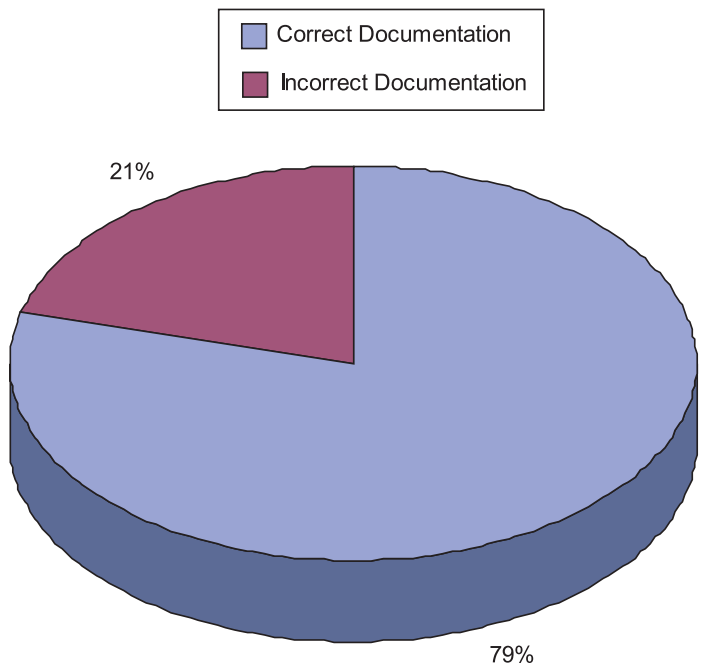

Fig 7: Distribution of FFP according to documentation

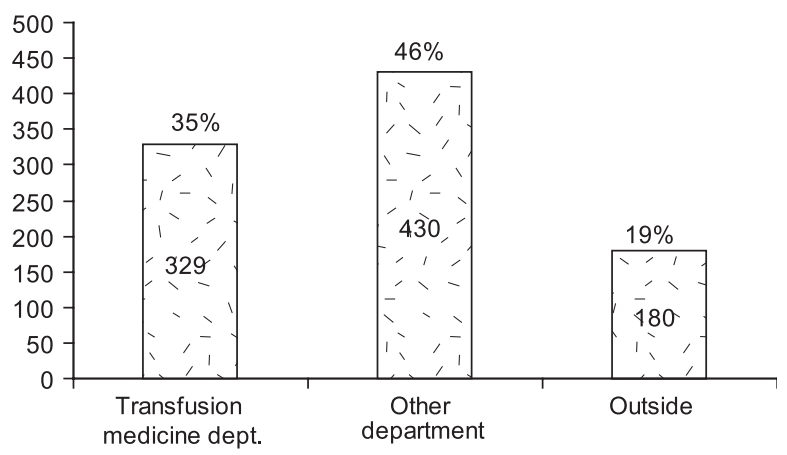

Fig 8: Distribution of FFP according to demand $(n=939)$

\section{Discussion:}

In this cross sectional study, it was observed that 939 units of FFP is required by 289 patients in different department of BSMMU during the period of Nov. 2008 to April 2009. Patients requiring FFP were between 1 day to 75 years. While most of them between 1 day to 10 years due to hereditary clotting disorder e.g. Hemophilia A, Hemophilia B, VWD ${ }^{3}$. Out of 289 patients 178 (61.59\%) were male and 111 $(38.41 \%)$ were female. The ratio of male is higher due to Hemophilia A where all affected child were male. Out of 289 patients, maximum, $111(38.41 \%)$ were B group, 86 $(29.76 \%)$ were O group, $66(22.84 \%)$ were A group and 26 (8.99\%) were AB group. These correlates with study of Rahman ${ }^{4}$.Out of 939 units of FFP maximum 329 (35.04\%) units were used in Day care center of transfusion medicine department, followed by Gastroenterology 188 (20.02\%), Burn \& plastic surgery 140(14.91\%) \& Paediatrics' \& allied 106 (11.29\%).

According to clinical indication, highest number of FFP Unit 271 (28.86\%) is used for Hemophilia A, followed by CLD 210 (22.36\%). It is interesting to see Burn 140(14.91\%) in top three clinical cause of FFP use. This doesn't match with data developed countries. Out of 939 units of FFP maximum 329 (35\%) units were consumed by Transfusion medicine department, and 430 (46\%) units by all other dept. of University. It indicates that BSMMU is consuming its $80 \%$ production. To face any national crisis we must have a high number of stocks. In this study it was found that a large 
number of unit 386 (41\%) use was not clinically justified. This mostly occurred in Burn cases where FFP was used as a volume expander fluid. Study also shows at least 1 in every 5 patient is supplied with requisition form that was lacked with necessary information.

\section{Conclusion and Recommendation:}

This Study concludes with recommendation of a "National Clinical Practice Guidelines" on the use of Blood components (PRBC, FFP, Platelets, Cryoprecipitate). That should be set up with representation from transfusion medicine, major clinical departments and the administration of GOB to oversee and regulate transfusion practice at national level. The guideline for use of blood/components must be made available to the end users along with more interaction by the transfusion service with the clinicians.

\section{Acknowledgements:}

We express our gratitude to all doctors and staffs of the Department of Transfusion Medicine of BSMMU and DMCH who helped us with the records during this research work.

\section{Reference:}

1. Mollison PL,Engelfriet CP,Contreras M (Eds). Blood transfusion in clinical medicine 11 th ed. Oxford: Blackwell. 1995. 329-333.

2. Cohen $\mathrm{H} \bullet$. Avoiding misuse of fresh frozen plasma. BMJ 1993; 307: 395-396.

3. Hoffbrand AV, Moss PAH, Petit JE. Essential Hematology, 5th ed. USA: Blackwell; 2006. p. 290-1.

4. Rahman M. Guide to blood Transfusion, 1st ed. Dhaka: Meghna Publications; 1978. p. 54-5. 